\title{
Variação do ângulo da câmera nas avaliações de amplitude articular por fotogrametria computadorizada
}

\author{
Camera angle variation in the range of motion's assessing by computerized photogrammetry \\ Variación del ángulo de la cámara en evaluaciones del rango articular mediante la \\ fotogrametría computarizada \\ Emanuelly Teixeira Barbosa da Costa', Fábio Cezar Bentes Mota², Rodrigo Luis Ferreira da Silva ${ }^{3}$
}

\begin{abstract}
RESUMO I A fotogrametria computadorizada tem se destacado como um recurso avaliativo não invasivo e de boa reprodutibilidade de resultados, contudo ainda carece de padronizações quanto aos parâmetros de sua aplicação. Este estudo comparou os resultados de análises fotogramétricas de amplitude articular obtidos a partir de imagens com diferentes inclinações da câmera fotográfica, em relação ao objeto (totalmente frontal ou $0^{\circ}, 5^{\circ}, 10^{\circ}, 15^{\circ}, 22^{\circ}, 25^{\circ}$ e 30). As imagens foram analisadas pela técnica da fotogrametria computadorizada e por seis examinadores que realizaram a quantificação de uma medida angular presente nas imagens. Os resultados demostraram que mesmo com uma variação de $5^{\circ}$ de inclinação de câmera, observou-se a presença de resultados significativamente diferentes entre as avaliações, com a margem de erro aumentando, conforme se acentuou a inclinação da câmera.
\end{abstract}

Descritores | Amplitude de Movimento Articular; Fotogrametria; Avaliação.

ABSTRACT | The computerized photogrammetry has been highlighted as a non-invasive resource for evaluation, with good reproducibility of results, but its application parameters are still lacking standardization. This study compared outcomes of range of motion obtained with photogrammetric assessments from images photographed in different camera inclinations in relation to the object $\left(0^{\circ}, 5^{\circ}, 10^{\circ}, 15^{\circ}, 20^{\circ}, 25^{\circ}\right.$, and $\left.30^{\circ}\right)$. The images were analyzed with computerized photogrammetry by six raters who assessed the joint range present in the images. The outcomes showed that even with $5^{\circ}$ in camera inclination, there was significantly different results between assessments, and the margin of error increased as the camera inclination was intensifying.

Keywords | Range of Motion; Photogrammetry; Assessment.

RESUMEN | La fotogrametría computarizada se ha destacado como un recurso evaluativo no invasivo y con buena reproducibilidad de resultados; sin embargo, aún carece de estándares en cuanto a los parámetros de su aplicación. Este estudio comparó los resultados de los análisis fotogramétricos del rango articular, obtenidos a partir de imágenes con distintas inclinaciones de la cámara fotográfica en relación al objeto (totalmente frontal o $0^{\circ}, 5^{\circ}, 10^{\circ}, 15^{\circ}, 20^{\circ}$, $25^{\circ}$ y $30^{\circ}$ ). Las imágenes fueron analizadas por la técnica de fotogrametría computarizada y por seis examinadores que realizaron la cuantificación de una medida angular presente en ellas. Los resultados mostraron que incluso con una variación de $5^{\circ}$ de inclinación de la cámara se observó resultados significativamente distintos entre las evaluaciones, aumentando el margen de error, mientras se acentuaba la inclinación de la cámara.

Palabras clave | Rango del Movimiento Articular; Fotogrametría; Evaluación.

'Universidade do Estado do Pará (Uepa) - Santarém (PA), Brasil. E-mail: manu2016fisio@gmail.com. Orcid: 0000-0003-4157-0993 2Universidade do Estado do Pará (Uepa) - Santarém (PA), Brasil. E-mail: fabiocezarbentesmota@gmail.com. Orcid: 0000-0002-0029-549X 3Universidade do Estado do Pará (Uepa) - Santarém (PA), Brasil. E-mail: rodrigolfs@uepa.br. Orcid: 0000-0003-2430-0473 


\section{INTRODUÇÃO}

O uso de novas tecnologias e métodos que permitam a obtenção de medidas do corpo e dos gestos humanos, os quais possibilitem a interpretação dos parâmetros biomecânicos de forma clara, dinâmica e confiável, tem se tornado um desafio para estudiosos desta área de conhecimento. Nesse contexto, a fotogrametria computadorizada se destaca nas últimas décadas como uma técnica de grande difusão e aceitação por parte dos profissionais da análise do movimento ${ }^{1}$, sendo considerado um recurso avaliativo não invasivo, de baixo custo, alta precisão e de boa reprodutibilidade dos resultados ${ }^{2,3}$.

Desde o seu surgimento, a fotogrametria computadorizada vem demonstrando grande versatilidade, com potencial para inúmeras aplicações, como por exemplo: realizar avaliações posturais ${ }^{4-6}$; avaliar a flexibilidade de indivíduos ${ }^{7}$; quantificar os ângulos articulares, ou Amplitudes de Movimento (ADM) ${ }^{3,8}$; e realizar análise e padronização morfométrica ${ }^{9,10}$.

Apesar das inúmeras vantagens e potencialidades desta técnica avaliativa, ao se analisar alguns dos principais estudos nacionais sobre a temática ${ }^{2,3,11,12}$, fica notória a falta de uma padronização quanto ao posicionamento da câmera em relação ao objeto a ser fotografado, no que tange a captura das imagens a serem analisadas, ainda que haja alguns estudos desenvolvidos neste sentido ${ }^{13,14}$.

Em vista disso, torna-se essencial que novas pesquisas continuem sendo desenvolvidas, com intuito de agregar seus resultados até que apontem em uma direção uniforme quanto à adequação para o posicionamento de câmera.

Diante disso, o objetivo deste trabalho foi comparar os resultados de análises fotogramétricas de ADM, obtidos a partir de imagens com diferentes inclinações transversais da câmera fotográfica, em relação ao objeto.

\section{METODOLOGIA}

A amostra foi dividida em duas categorias: (1) Examinadores; e (2) Imagens digitalizadas a serem analisadas. Para a constituição da amostra de examinadores foi necessário realizar a capacitação prévia (Workshop de 8 h) deste público (concluintes do curso de Fisioterapia), a fim de garantir uma habilidade e experiência similar quanto à utilização dos softwares em fotogrametria computadorizada. Este treinamento foi realizado por um profissional com formação e experiência na área.
Após a aplicação do referido treinamento, os acadêmicos foram então apresentados aos objetivos do estudo e a sua proposta metodológica. Em seguida, foram solicitados a assinarem o Termo de Consentimento Livre e Esclarecido. De um total de 9 voluntários capacitados, 6 indivíduos foram selecionados para compor este grupo.

Um cálculo amostral, utilizando o valor de desvio padrão de 0.541 para medidas de ADM obtidas por fotogrametria computadorizada em um estudo similar anterior ${ }^{14}$, definiu a necessidade de no mínimo 18 imagens a serem analisadas, para cada posição de câmera que foi experimentada no presente estudo, com o intuito de garantir a validade estatística desta amostra e a reprodutibilidade deste estudo.

Quanto aos objetos a serem fotografados, optou-se por confeccionar banners com imagens em tamanho real do membro superior de um indivíduo, posicionado em pé e em perfil, com a articulação do cotovelo em ângulos variados. Marcadores de superfície foram previamente posicionados sobre a borda lateral do acrômio, epicôndilo lateral do úmero e processo estilóide do rádio. Foram utilizadas 8 diferentes posições angulares do cotovelo e, portanto, foram confeccionados 8 banners.

Os banners com as imagens do indivíduo em flexão de cotovelo foram fixados (um de cada vez) em uma parede, voltados para a câmera fotográfica (Nikon Coolpix L810, com resolução de 16.1 megapixels), posicionada em um tripé, a uma distância de $2,4 \mathrm{~m}$ do objeto analisado, de acordo com a descrição de Iunes et al. ${ }^{11,15}$, e na altura da articulação do cotovelo visualizada no banner, acatando ao sugerido por Ricieri ${ }^{13}$ (Figura 1 ).

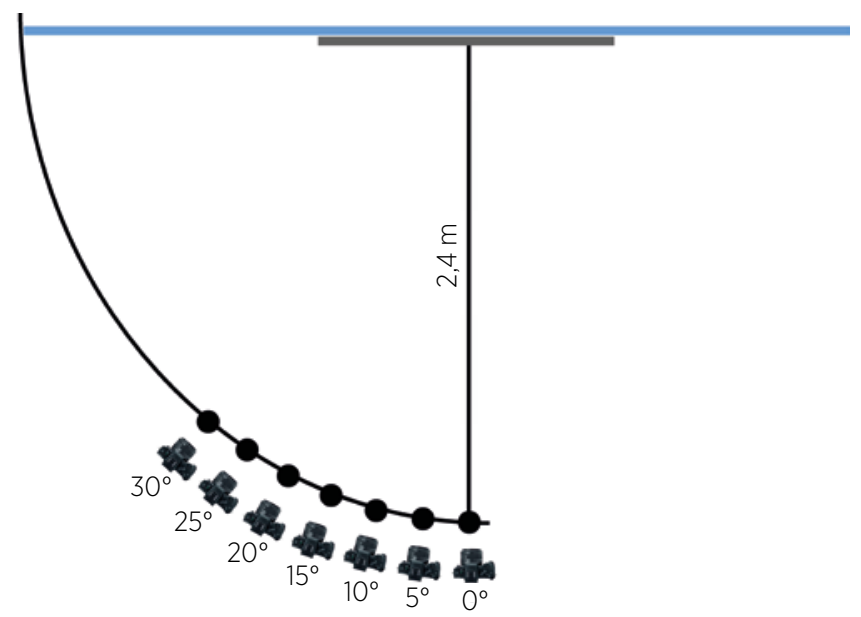

Figura 1. Protocolo de posicionamento da câmera para os registros fotográficos

Mantendo-se estes parâmetros de posicionamento e variando-se apenas o ângulo da câmera em relação ao 
objeto a ser fotografado, foram então realizados registros fotográficos de cada um dos 8 banners, em cada uma das 7 angulações de câmera experimentadas $\left(0^{\circ}, 5^{\circ}, 10^{\circ}, 15^{\circ}\right.$, $20^{\circ}, 25^{\circ}$ e $30^{\circ}$ ) (Figura 2 ).

As imagens digitais obtidas foram transferidas para notebooks equipados com 3 dos softwares mais empregados para análise fotogramétrica (CorelDraw, AutoCAD e Image J). Por conseguinte, o grupo de examinadores foi convocado para realizar as análises das ADM do cotovelo do modelo fotografado, utilizando a fotogrametria computadorizada. Estas análises ocorreram em três dias não consecutivos (intervalo de três dias entre si), para evitar que os examinadores memorizassem os resultados de suas avaliações. É importante ressaltar que em todos os dias de análises, os examinadores receberam o mesmo conjunto de imagens. Porém, tais imagens foram renomeadas e ordenadas de formas totalmente diferentes nas pastas digitais.

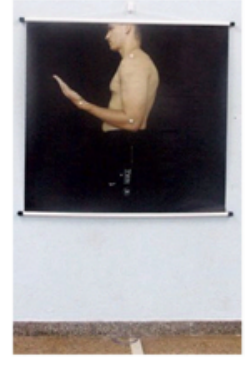

$0^{\circ}$

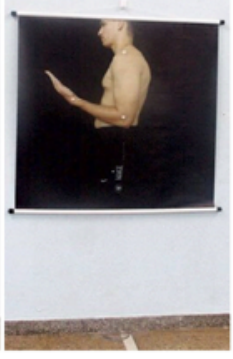

$5^{\circ}$

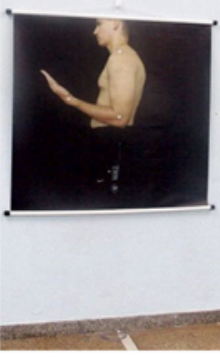

$10^{\circ}$

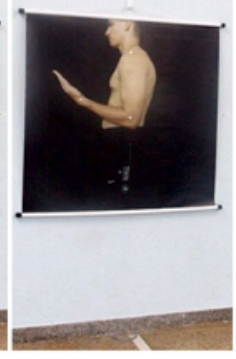

$15^{\circ}$

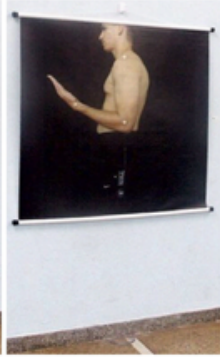

$20^{\circ}$

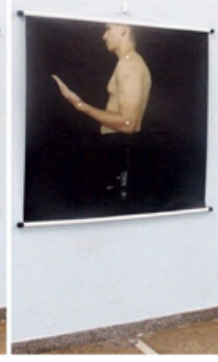

$25^{\circ}$

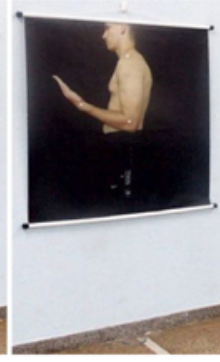

$30^{\circ}$

Figura 2. As sete angulações de câmera experimentadas

Também é oportuno esclarecer que apesar dos examinadores terem sido solicitados a realizar as análises fotogramétricas de várias posições angulares de articulações do cotovelo, apenas um destes ângulos foi levado em consideração para as análises de variância e para responder aos objetivos desta pesquisa. Este ângulo-chave foi definido pelos pesquisadores, porém os examinadores não foram informados sobre sua existência.

Os resultados destas análises foram posteriormente tabulados e sua análise estatística foi realizada com o BioEstat 5.4. A estatística descritiva serviu para caracterizar o conjunto de dados das análises fotogramétricas. Quanto à análise da normalidade dos dados, esta foi realizada aplicando-se o teste Shapiro-Wilk e apontou para o emprego de testes de análise variância não-paramétricos (Kruskal-Wallis para a análise de variância interexaminador e Friedman para a análise de variância intraexaminador). Por fim, para testar a variância entre as medidas angulares obtidas de imagens fotografadas em diferentes posicionamentos angulares da câmera fotográfica, novamente utilizou-se o teste de KruskalWallis. O nível de significância estabelecido foi de 5\%, a fim de manter-se a cientificidade da pesquisa.

\section{RESULTADOS}

Primeiramente, foi necessário estabelecer se algum dos softwares em prova (AutoCAD, Corel Draw ou ImageJ) poderia favorecer a obtenção de resultados inconsistentes. Da mesma maneira, também foi necessário estabelecer se algum dos seis examinadores selecionados apresentaria resultados inconsistentes de suas análises fotogramétricas (Tabela 1).

A Tabela 2 apresenta a estatística descritiva e a normalidade das medidas fotogramétricas obtidas pelos examinadores com o software Corel Draw, a partir de imagens da articulação do cotovelo obtidas com a câmera fotográfica em diferentes inclinações.

Tabela 1. Valores de significância das análises de variância das avaliações fotogramétricas

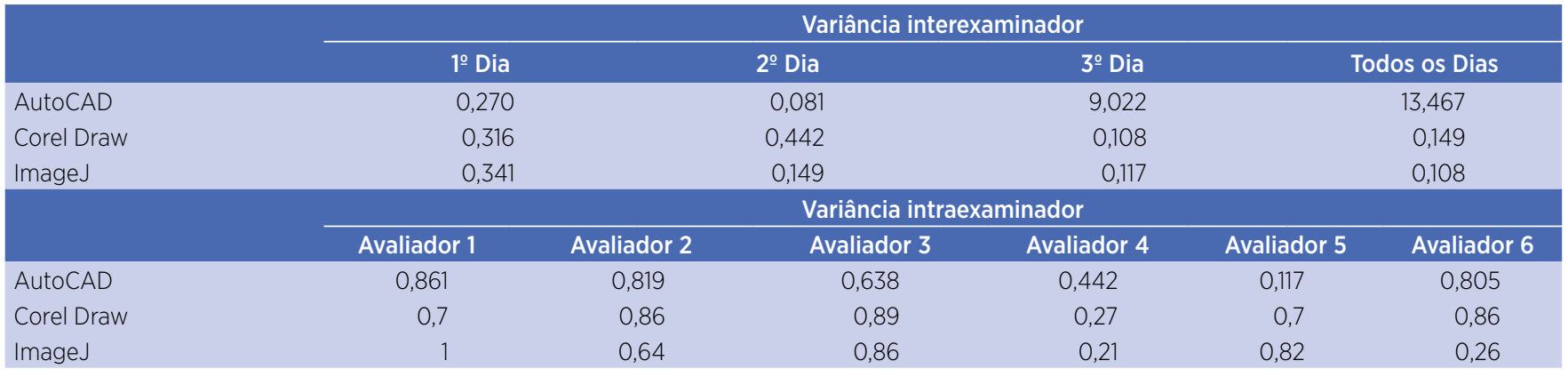


Tabela 2. Estatística descritiva e normalidade dos dados das análises fotogramétricas

\begin{tabular}{|c|c|c|c|c|c|c|c|}
\hline Inclinações & $0^{\circ}$ & $5^{\circ}$ & $10^{\circ}$ & $15^{\circ}$ & $20^{\circ}$ & $25^{\circ}$ & $30^{\circ}$ \\
\hline n & 18 & 18 & 18 & 18 & 18 & 18 & 18 \\
\hline Mín. & 66 & 66 & 66 & 66 & 67 & 66 & 67 \\
\hline Máx. & 69 & 69 & 70 & 69 & 70 & 70 & 70 \\
\hline Média & 67,22 & 67,33 & 68,17 & 68,17 & 68,55 & 68,83 & 68,94 \\
\hline $\mathrm{DP}$ & 0,73 & 0,84 & 0,86 & 1,04 & 0,78 & 0,92 & 0,80 \\
\hline Shapiro-Wilk & 0,82 & 0,84 & 0,83 & 0,77 & 0,82 & 0,76 & 0,84 \\
\hline$p$ & 0,01 & 0,01 & 0,01 & 0,01 & 0,01 & 0,01 & 0,01 \\
\hline
\end{tabular}

p: nivel de significância do teste.

A Tabela 3 demonstra todas as comparações entre medidas angulares realizadas por fotogrametria computadorizada nas diferentes inclinações de câmera testadas neste experimento. São apontadas nesta tabela entre quais comparações foi possível identificar se houve uma variação significante dos valores angulares obtidos por fotogrametria computadorizada.

Tabela 3. Variância entre medidas angulares a partir de imagens com diferentes variações do posicionamento angular transversal da câmera fotográfica

\begin{tabular}{|c|c|c|c|}
\hline & $\begin{array}{l}\text { Comparações entre } \\
\text { inclinações de câmera }\end{array}$ & p & $\begin{array}{c}\% \text { de } \\
\text { variâncias } \\
\text { significativas }\end{array}$ \\
\hline \multirow{6}{*}{ Variações de $5^{\circ}$} & $25^{\circ} \times 30^{\circ}$ & 0,836 & \multirow{6}{*}{$16,66 \%$} \\
\hline & $20^{\circ} \times 25^{\circ}$ & 0,380 & \\
\hline & $15^{\circ} \times 20^{\circ}$ & 0,345 & \\
\hline & $10^{\circ} \times 15^{0}$ & 0,797 & \\
\hline & $05^{\circ} \times 10^{\circ}$ & $0,029^{*}$ & \\
\hline & $00^{\circ} \times 05^{\circ}$ & 0,742 & \\
\hline \multirow{5}{*}{ Variações de $10^{\circ}$} & $20^{\circ} \times 30^{\circ}$ & 0,277 & \multirow{5}{*}{$40 \%$} \\
\hline & $15^{\circ} \times 25^{\circ}$ & 0,068 & \\
\hline & $10^{\circ} \times 20^{\circ}$ & 0,229 & \\
\hline & $05^{\circ} \times 15^{\circ}$ & $0,015^{*}$ & \\
\hline & $00^{\circ} \times 10^{\circ}$ & $0,012^{*}$ & \\
\hline \multirow{4}{*}{ Variações de $15^{\circ}$} & $15^{\circ} \times 30^{\circ}$ & $0,042^{*}$ & \multirow{4}{*}{$100 \%$} \\
\hline & $10^{\circ} \times 25^{\circ}$ & $0,037^{*}$ & \\
\hline & $05^{\circ} \times 20^{\circ}$ & $0,001^{*}$ & \\
\hline & $00^{\circ} \times 15^{\circ}$ & $0,006^{*}$ & \\
\hline \multirow{3}{*}{ Variações de $20^{\circ}$} & $10^{\circ} \times 30^{\circ}$ & $0,022^{*}$ & \multirow{3}{*}{$100 \%$} \\
\hline & $05^{\circ} \times 25^{\circ}$ & $0,000^{*}$ & \\
\hline & $00^{\circ} \times 20^{\circ}$ & $0,000^{*}$ & \\
\hline \multirow{2}{*}{ Variações de $25^{\circ}$} & $05^{\circ} \times 30^{\circ}$ & $0,000^{*}$ & \multirow{2}{*}{$100 \%$} \\
\hline & $00^{\circ} \times 25^{\circ}$ & $0,000^{*}$ & \\
\hline Variação de $30^{\circ}$ & $00^{\circ} \times 30^{\circ}$ & $0,000^{*}$ & $100 \%$ \\
\hline
\end{tabular}

p: nivel de significância do teste; *variâncias significativas.

\section{DISCUSSÃO}

Os dados da Tabela 1 apontam que nenhum dos softwares favoreceu a obtenção de resultados inconsistentes, uma vez que não foi observada uma variação significativa de seus resultados em nenhum dos dias de análise.

Guariglia et al. ${ }^{16}$ atestaram boa confiabilidade para os softwares SAPO, AutoCAD e Corel Draw em análises fotogramétricas para medida angular do quadril, sugerindo que a escolha seja feita pela familiaridade do pesquisador com cada um destes. Bons resultados de confiabilidade e precisão diagnóstica acerca dos programas $\mathrm{SAPO}$, AutoCAD e Corel Draw também foram confirmados na revisão de Furlanetto et al. ${ }^{4}$, que objetivou avaliar os procedimentos matemáticos empregados por diferentes softwares já validados para a avaliação postural por fotogrametria computadorizada. Em relação ao software ImageJ, a exploração da literatura demonstrou que sua aplicação para análises de postura e $\mathrm{ADM}$ é menos frequente, contudo, sua aplicação é bastante destacada em estudos de avaliação morfométrica, na qual ele é empregado para a identificação, quantificação e mensuração de estruturas ${ }^{9,10}$.

Além da confiabilidade dos softwares, Guariglia et al. ${ }^{16}$ salientam a importância da experiência prévia dos examinadores quanto ao seu uso para realizar análises fotogramétricas, tal como foi evidenciado no experimento de Paes et al. ${ }^{6}$. Estes autores declaram que a familiarização se torna ainda mais necessária em se tratando de softwares como AutoCAD e Corel Draw, os quais não foram originalmente idealizados para esta prática. Esta mesma opinião é compartilhada por vários outros autores ${ }^{17,18}$, os quais reafirmam que a menor experiência de um examinador com o software escolhido para uma análise fotogramétrica fragiliza a confiabilidade desta análise.

De maneira geral, esta dificuldade costuma ser superada com um pequeno treinamento específico sobre a utilização das ferramentas do software, tal como se observou no estudo de Batista et al. ${ }^{19}$ e Gutterres ${ }^{20}$. Também foi constatado na presente investigação que nenhum dos examinadores apresentou resultados inconsistentes de suas análises (Tabela 1), definindo assim que o treinamento realizado previamente foi suficiente e eficaz para a sua qualificação. 
Contudo, ao apreciar as revisões de Furlanetto et al. ${ }^{4} \mathrm{e}$ Singla et al. ${ }^{5}$,é notório que além da competência quanto a utilização do software para a análise fotogramétrica, a experiência técnica dos examinadores quanto aos procedimentos protocolares da avaliação (o correto posicionamento do avaliado e a identificação de pontos anatômicos de referência em avaliações posturais ou de ADM, por exemplo) é igualmente relevante. Tal afirmação encontra sustentação nas conclusões de Carneiro et al. ${ }^{17}$ e Gutterres ${ }^{20}$ que atribuíram resultados de baixa confiabilidade interexaminador em seus estudos à heterogeneidade de experiência de seus examinadores, em relação aos procedimentos técnicos da avaliação.

O conhecimento deste fato foi fator decisivo para o planejamento metodológico da presente pesquisa, retirando dos examinadores a responsabilidade técnica quanto ao posicionamento do avaliado e dos marcadores de superfície corporal, evitando assim o viés de procedimento.

Uma vez tendo identificado que tanto os 3 softwares em prova, quanto os 6 examinadores selecionados apresentavam consistência suficiente de resultados, a etapa seguinte desta pesquisa ocorreu com a comparação de medidas angulares do cotovelo de imagens fotografadas em diferentes inclinações de câmera, utilizando o software Corel Draw, após uma escolha democrática entre os examinadores.

Ao observar os resultados da Tabela 2, percebe-se que o valor angular médio identificado pelos examinadores, para a posição do cotovelo, foi de aproximadamente $67^{\circ}\left(67,22^{\circ}\right)$ para fotogramas obtidos com a câmera posicionada frontalmente em relação ao objeto (posição $0^{\circ}$ ). Tal valor angular nitidamente demonstra um distanciamento deste valor inicial, à medida que a inclinação da câmera aumenta, chegando à angulação média de quase $69^{\circ}\left(68,94^{\circ}\right)$, com a câmera inclinada em $30^{\circ}$ em relação ao objeto fotografado.

De acordo com Ricieri ${ }^{21}$ para a fotointerpretação angular, as distorções de imagem podem se tornar fator de inutilização da análise, sendo importante a validação do instrumento e do método. Iunes et al. ${ }^{11}$ são igualmente taxativos ao afirmarem que o emprego adequado da técnica de fotogrametria computadorizada requer vários cuidados metodológicos para padronizar as fotos e evitar efeitos de distorção, uma vez que tais efeitos podem causar uma análise enganosa.

Sobre os resultados da Tabela 3, destaca-se primeiramente que mesmo no grupo de comparação o qual confrontava medidas angulares com uma variação de apenas $5^{\circ}$ de inclinação de câmera (menor variação testada neste experimento), observou-se a presença de variações significantes de resultados.
Em um estudo similar, Mota et al. ${ }^{22}$ procuraram investigar a interferência do posicionamento do objeto a ser fotografado, em relação ao plano da câmera. No referido estudo, um manequim articulado foi fotografado em diferentes posições (plano perpendicular e rotacionado para a direita e para a esquerda). A partir disso, foi verificado que as medidas obtidas sem a rotação do manequim obtiveram o menor erro e dispersão de mensuração, enquanto as rotações para a esquerda e para a direita apresentaram maiores erros do que no posicionamento frontal em relação à câmera.

Apesar da diferença metodológica entre o estudo de Mota et $\mathrm{al}^{22}$ e a presente pesquisa, é bastante claro que a intenção de ambos é semelhante e, portanto, seus resultados são facilmente comparáveis, tendo em vista que evidenciam o seguinte: mesmo pequenas variações de inclinação da câmera podem afetar a confiabilidade de análises fotogramétricas.

Outro fato facilmente percebido ao interpretar os dados desta tabela é que a frequência percentual de variações significantes aumentou gradativamente, conforme também se aumentava a variação de inclinação do posicionamento da câmera, atingindo $100 \%$ de variações significantes nas comparações, com diferença de $15^{\circ}$ de inclinação e superiores.

Mais uma vez o estudo de Mota et $\mathrm{al}^{22}$ acompanha os achados da presente investigação, uma vez que seus resultados também apontaram maior erro de medida fotogramétrica nas situações em que se testaram os maiores desalinhamentos entre a câmera e o objeto a ser fotografado ( $8^{\circ}$ para a direita e esquerda). Desta forma, os resultados de ambos os estudos indicam claramente que quanto maior o desalinhamento entre câmera e objeto a ser fotografado, maior será a distorção da imagem e, por conseguinte, maior a probabilidade de erro em medidas obtidas por fotogrametria computadorizada.

\section{CONCLUSÃO}

Conclui-se, portanto, que mesmo pequenas variações de inclinação da câmera podem afetar a confiabilidade de análises fotogramétricas e quanto maior o desalinhamento entre câmera e objeto a ser fotografado, maior será a distorção da imagem e a probabilidade de erro em medidas obtidas por fotogrametria computadorizada.

\section{REFERÊNCIAS}

1. Ey-Chmielewska H, Chruściel-Nogalska M, Fraczak B. Photogrammetry and its potential application in medical science on the basis of selected literature. Adv Clin Exp Med. 2015;24(4):737-41. doi: 10.17219/acem/58951 
2. Baraúna MA, Duarte F, Sanchez HM, Canto RST, Malusá S, Campelo Silva CD, Ventura Silva RA. Avaliação do equilíbrio estático em indivíduos amputados de membros Inferiores através da biofotogrametria computadorizada. Rev Bras Fisioter. 2006;10(1):83-90. doi: 10.1590/S1413-35552006000100011

3. César EP, Gomes PSC, Marques CL, Domingos BDP, Santos TM. Confiabilidade intra-avaliador da medida de amplitude de movimento da flexão e extensão do joelho pelo método de fotogrametria. Fisioter Pesqui. 2012;19(1):32-8. doi: 10.1590/S1809-29502012000100007

4. Furlanetto TS, Sedrez JA, Candotti CT, Loss JF. Photogrammetry as a tool for the postural evaluation of the spine: a systematic review. World J Orthop. 2016;7(2):136-48. doi: 10.5312/wjo.v7.i2.136

5. Singla D, Veqar Z, Hussain E. Photogrammetric assessment of upper body posture using postural angles: a literature review. J Chiropr Med. 2017;16(2):131-8. doi: 10.1016/j.jcm.2017.01.005

6. Paes JL, Piazza L, Tormen L, Libardoni TC, Pasquali T, Santos GM. Confiabilidade intra e interexaminador da avaliação do alinhamento da cabeça nas posições sentado e em pé. Fisioter Pesq. 2017;24(1):29-39. doi: 10.1590/1809-2950/15962824012017

7. Perin A, Ulbricht L, Ricieri DV, Neves EB. Utilização da biofotogrametria para a avaliação da flexibilidade de tronco. Rev Bras Med Esporte. 2012;18(3):176-80. doi: 10.1590/S1517-86922012000300008

8. Ferreira da Silva RL, Coelho RR, Barreto GA, Aguiar JP, Santos PO, Dantas EHM. Comparação entre a avaliação da amplitude articular estática do cotovelo por meio de três diferentes métodos: goniometria, biofotogrametria e goniometria da imagem radiológica. Fisioter Bras. 2009;10(2):106-12.

9. Defoe DM, Rao H, Harris III DJ, Moore PD, Brocher J, Harrison TA. A non-canonical role for $\mathrm{p} 27^{\mathrm{Kipl}}$ in restricting proliferation of corneal endothelial cells during development. PLOS ONE. 2020;15(1):e0226725. doi: 10.1371/journal.pone.0226725

10. Kachooei SA, Rahmani R, Zareh N, Donyadideh F, Kachooei SA, Nabiuni M, Yazdansetad S. Down-regulation of TGF- $\beta$, VEGF, and bFGF in vascular endothelial cells of chicken induced by a brittle star (Ophiocoma erinaceus) extract. Heliyon. 2020;6(1):e03199. doi: 10.1016/j.heliyon.2020.e03199

11. Iunes DH, Castro FA, Salgado HS, Moura IC, Oliveira AS, Bevilaqua-Crossi D. Confiabilidade intra e interexaminadores e repetibilidade da avaliação postural pela fotogrametria. Rev Bras Fisioter. 2005;9(3):327-34

12. Alves RS, Pereira IC, lunes DH, Rocha CBJ, Botelho S, Carvalho LC. Intra and inter-rater reliability of the projection of the body's center of mass obtained via photogrammetry. Fisioter Bras. 2017;24(4):349-55. doi: 10.1590/1809-2950/15819124042017

13. Ricieri DV. Princípios processuais da biofotogrametria e sua adaptação para medidas em estudos sobre movimentos respiratórios toracoabdominais [thesis]. Curitiba: Universidade Federal do Paraná; 2008.

14. Amazonas DR. Padronizações para avaliação em fotogrametria computadorizada: posicionamento de câmera e utilização de programas [dissertation]. Santarém: Universidade do Estado do Pará; 2010.

15. Iunes DH, Bevilaqua-Grossi D, Oliveira AS, Castro FA, Salgado HS. Análise comparativa entre avaliação postural visual e por fotogrametria computadorizada. Rev Bras Fisioter. 2009;13(4):308-15. doi: 10.1590/S1413-35552009005000039

16. Guariglia DA, Pereira LM, Pereira HM, Cardoso JR. Avaliação da confiabilidade e usabilidade de três diferentes programas computacionais para a análise fotogramétrica do ângulo de flexão de quadril. Fisioter Pesqui. 2011;18(3):247-51. doi: 10.1590/S1809-29502011000300008

17. Carneiro PR, Cardoso BS, Cunha CM, Teles LC. Reliability intra-and inter-examiner of the head postural assessment by computerized photogrammetry. Fisioter Pesqui. 2014;21(1):34-9. doi: 10.1590/1809-2950/402210114

18. Rocha EAB, Baroni MP, Pereira ALS, Assis SJC, Dantas DS. Confiabilidade inter e intraexaminador da fotogrametria computadorizada por meio do software AutoCAD ${ }^{\circledR}$ R12. Conscientiae Saúde. 2015;14(4):617-26. doi: 10.5585/ ConsSaude.v14n4.5730

19. Batista LH, Camargo PR, Aiello GV, Oishi J, Salvini TF. Avaliação da amplitude articular do joelho: correlação entre as medidas realizadas com o goniômetro universal e no dinamômetro isocinético. Rev Bras Fisioter. 2006;10(2):193-8. doi: 10.1590/S1413-35552006000200009

20. Gutterres DMM. Proposta e implementação de uma ferramenta para análise de imagens de retinografia digital [dissertation]. Porto Alegre: Universidade Federal do Rio Grande do Sul; 2010.

21. Ricieri DV. Validação de um protocolo de fotogrametria computadorizada e quantificação angular do movimento tóraco-abdominal durante a ventilação tranquila [dissertation]. Uberlândia: Centro Universitário do Triangulo; 2000.

22. Mota YL, Mochizuki L, Sales DBO, Martins MG, Carvalho GA. A rotação do voluntário e a calibração influenciam as medidas mensuradas por meio da fotogrametria. Rev Bras Ciênc Mov. 2014;22(1):30-6. doi: 10.18511/0103-1716/rbcm.v22n1p30-36 